\title{
RESSURREIÇÃO E MEDIDA POR MEDIDA: A IRONIA NAS RELAÇÕES INTERTEXTUAIS
}

\section{ANA CAROLINA SÁ TELES}

Pesquisadora independente

São Paulo, São Paulo, Brasil

Resumo: No artigo, investiga-se como o diálogo de Ressurreição com o tropo da "quase ressurreição" em Medida por medida, de Shakespeare, constitui uma chave para compreender a ironia no título do livro de 1872 e no logro dos protagonistas, bem como o arranjo da constelação de personagens. Observase que Ressurreição estabeleceu relações de intertextualidade e ironia tanto com paradigmas da prosa romântica do século XIX quanto com recursos antigos, como o costume retórico dos caracteres e o tema da ressurreição shakespeariana.

Palavras-chave: Caracteres; Constelação de personagens; Ressurreição shakespeariana.

\section{RESURRECTION AND MEASURE FOR MEASURE: THE IRONY IN INTERTEXTUALITY}

\begin{abstract}
This article investigates how the dialogue between Machado de Assis's Resurrection and the theme of quasi resurrection in Shakespeare's Measure for Measure is key to understanding the humor in the title of Machado's book published in 1872 and of the frustrating ending for the protagonists, as well as the arrangement of the constellation of characters. We observe that Resurrection developed intertextuality and irony concerning not only the narrative patterns of nineteenth century romantic prose, but also the rhetoric of the characters and the theme of Shakespearean resurrection.
\end{abstract}

Keywords: Characters; Character constellation; Shakespearean resurrection. 


\section{O prólogo de Ressurreição versus os prólogos contritos e singelos: caracteres e diferença}

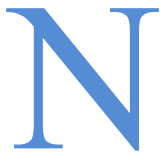
a "Advertência" de Ressurreição, Machado de Assis enfatiza sua estreia no gênero romance. Observamos, contudo, que seu projeto narrativo se apresenta de forma negativa. Nas palavras do autor, o livro seria um “ensaio" (ASSIS, 2008, p. 235), e o exercício nos gêneros, restrito à "reflexão" (ASSIS, 2008, p. 236). Em especial, encontramos na "Advertência" o movimento do romance machadiano de se diferenciar da prosa romântica em voga (GUIMARÃES, 2004, p. 125-26).

No início do prólogo o autor especula: "Não sei o que deva pensar deste livro; ignoro sobretudo o que pensará dele o leitor" (ASSIS, 2008, p. 235). Por um lado, a conjectura realça a dessemelhança da obra. Por outro lado, ela se relaciona ao embate entre os pares na trama. $\mathrm{O}$ desconhecimento do outro (incluindo-se aquele que habita a mesma pessoa) potencializa o contraste de caracteres. No plano temático de Ressurreição, as personagens têm perspectivas discordantes sobre o amor romântico e o casamento. Por sua vez, no plano enunciativo, o autor implícito e o narrador se opõem ao leitor virtual e ficcional no que tange às práticas românticas. A narrativa dialoga com elas, ao mesmo tempo em que as frustra. Ao envolver o livro numa aura de "ensaio", o autor propõe uma aprendizagem também ao leitor. Enquanto as personagens têm a tarefa de se conhecer, o leitor vivencia um desafio semelhante. Trata-se da recepção de procedimentos narrativos que levam ao estranhamento de padrões do romance romântico e, potencialmente, à reflexão sobre eles.

O desconhecimento do outro ramifica-se nos temas da dissimulação e da desconfiança. A dissimulação compõe um traço distintivo na caracterização das personagens de Ressurreição, enquanto a desconfiança é figurada principalmente em dois registros. Ora é expressa como prevenção contra o engano de outrem. Ora, como traço subjetivo. No primeiro caso mostra-se válida quando Raquel e Viana desmascaram Luís Batista. No segundo caso, ocorre quando Félix é dominado pela dúvida. Na "Advertência”, os mesmos problemas são abordados:

A crítica desconfia sempre da modéstia dos prólogos, e tem razão. Geralmente são arrebiques de dama elegante, que se vê ou se crê bonita, 
e quer assim realçar as graças naturais. Eu fujo e benzo-me três vezes quando encaro alguns desses prefácios contritos e singelos, que trazem os olhos no pó da sua humildade, e o coração nos píncaros da sua ambição. (ASSIS, 2008, p. 235)

A imagem contrasta o alto e baixo, antecipando a parábola do astrólogo e da velha, no capítulo $\mathrm{V}$, que contrapõe os caracteres de tendência quimérica aos caracteres de tendência prática. Porém, na "Advertência", a relação entre imagem interna e externa é ambivalente. Ao mesmo tempo em que os olhos se dão a ver, estão impregnados da perspectiva do sujeito. Ou seja, têm um coração escondido: "Quem só lhes vê os olhos, e lhes diz verdade que amargue, arrisca-se a descair no conceito do autor, sem embargo da humildade que ele mesmo confessou, e da justiça que pediu" (ASSIS, 2008, p. 235). Assim, a dissimulação encontra um limite no confronto com a alteridade.

A "Advertência" desenha uma dinâmica complexa para dramatizar o contraste entre os prefácios dissimulados e a "crítica sisuda" (ASSIS, 2008, p. 235). Não obstante, converge para tipos, valendo-se do costume retórico dos caracteres. Este remonta a um gênero praticado por Teofrasto no século IV a.C. e por uma rede de escritos entre os séculos XVII e XVIII que inclui os satiristas ingleses e La Bruyère. Resumidamente, os caracteres teofrásticos compõem perfis típicos em função de uma qualidade psicológica negativa como: "o dissimulado", "o inconstante”, “o descontente” e "o bajulador". Em oposição aos caracteres, há a descrição pelo retrato, que objetiva à figuração de indivíduos. Não obstante, as duas modalidades podem mesclar-se de forma insolúvel (A BOOK OF "CHARACTERS", 1924, p. 1).

Além do paradoxo compartilhado pelas duas técnicas de desenho verbal, há ambivalência no que diz respeito à concepção das personagens machadianas. Trata-se do binômio de "caracteres" e "sentimentos" que Machado de Assis demanda à composição da personagem, desde sua crítica dos anos 1860 e 1870, especialmente em "Literatura realista" e "Notícia da atual literatura brasileira: Instinto de nacionalidade". Nos ensaios, Machado defende o delineamento do caráter da personagem, bem como a figuração dos sentimentos que a particularizam. Por esse motivo, observamos que na "Advertência" tão importante quanto a tipificação dos outros prólogos é o gesto de se diferenciar:

Ora pois, eu atrevo-me a dizer à boa e sisuda crítica que este prólogo não se parece com esses prólogos. [...] O que eu peço à crítica vem a ser intenção benévola, mas expressão franca e justa. Aplausos, quando os não 
fundamenta o mérito, afagam certamente o espírito, e dão algum verniz de celebridade; mas quem tem vontade de aprender e quer fazer alguma cousa, prefere a lição que melhora ao ruído que lisonjeia. (ASSIS, 2008, p. 235)

As formulações sobre a produção literária na "Advertência" são paralelas a conceitos trabalhados pela crítica de autoria de Machado de Assis. Em "O ideal do crítico" (1865), notadamente, abordam-se os temas da opinião pública, do capricho, da volubilidade e do amor-próprio, que se opõem à crítica conscienciosa (2013, p. 237-38). Portanto, a "Advertência" constitui uma carta aberta ao público em que se condensam tanto o projeto estético de Ressurreição, quanto os pressupostos da carreira do escritor em suas décadas iniciais. Ao esclarecer o intuito do romance, o autor parece promover um corte:

Minha ideia ao escrever este livro foi pôr em ação aquele pensamento de Shakespeare:

Our doubts are traitors

And make us lose the good we oft might win

By fearing to attempt.

Não quis fazer romance de costumes; tentei o esboço de uma situação e o contraste de dous caracteres; com esses simples elementos busquei o interesse do livro. A crítica decidirá se a obra corresponde ao intuito, e sobretudo se o operário tem jeito para ela.

É o que lhe peço com o coração nas mãos. (ASSIS, 2008, p. 236)

No fundo, trata-se de uma continuidade. Os temas-chave da dúvida e do contraste de caracteres aparecem codificados na discussão sobre a escrita e a recepção literárias. $\mathrm{O}$ desconhecimento de si e do outro, a dúvida subjetiva e a dissimulação se alimentam. Para romper com o automatismo, pelo menos no âmbito estético, Machado pondera: "Com o tempo, adquire a reflexão o seu império, e eu incluo no tempo a condição do estudo, sem o qual o espírito fica em perpétua infância” (ASSIS, 2008, p. 235).

A reflexão oferece uma alternativa contra a confiança cega. Esta se aproxima de uma atitude correlata e oposta: a desconfiança indiscriminada. A atmosfera de desconhecimento e desconfiança descreve a situação de Félix. $\mathrm{O}$ “contraste de caracteres" oferece os meios pelos quais ele vive uma situação de aprendizagem. O desafio para o protagonista coloca-se em termos de um 
estudo do próprio comportamento e de seus pares. Portanto, os procedimentos estilísticos de caracterização das personagens e os temas estruturantes da trama de Ressurreição são apresentados de forma antecipada na "Advertência".

\section{2. "No dia de Ano-Bom": Félix e sua constelação de personagens}

No capítulo inicial, Félix é associado ao sol. A comparação remete ao modelo tradicional de organização das personagens na literatura ocidental. Nesta, o protagonista reúne os demais em torno de si de forma hierárquica (TRÖHLER, 2010, p. 406). A constelação de personagens de uma obra narrativa deve ser compreendida como um processo de abstração por parte do leitor. Ao construirmos uma imagem mental da constelação de personagens, apreendemos o esquema de relações entre as personagens na trama, bem como o significado dessas mesmas relações:

Uma constelação de personagens é, contudo, mais que a soma de todas as personagens. Sua estrutura é determinada por todas as relações entre as personagens: relações de importância; correspondências e contrastes de propriedades e funções; interação e comunicação; conflito e concordância; ver e ouvir mutuamente; anseios e desejos; poder e sistema de valores; narrar e ser narrado; perspectiva e participação. (EDER et al., 2010, p. 26, tradução nossa)

$\mathrm{Na}$ cena do dia de Ano-Bom, delineiam-se aspectos limítrofes. A ocasião é pautada por reflexões do narrador. Por um lado, os mais velhos se lembram do "fervor" dos mais novos (ASSIS, 2008, p. 36). Por outro lado, essa percepção seria ilusória: "e, alegres com vermos o ano que desponta, não reparamos que ele é também um passo para a morte” (ASSIS, 2008, p. 236). Assim, o sol do primeiro dia do ano é visto com a ressalva da mortalidade. Igualmente, sugere-se um percurso ilusório para o protagonista: "Teria esta última ideia entrado no espírito de Félix, ao contemplar a magnificência do céu e os esplendores da luz? Certo é que uma nuvem ligeira pareceu toldarlhe a fronte" (ASSIS, 2008, p. 236-237). Apesar do questionamento, o narrador não responde se Félix teria pensando na morte. Apenas menciona a nuvem que faz sombra em seu rosto, indicando o encobrimento de sua reflexão. Adicionalmente, a imagem é descrita pela contradição entre o "certo" e o aparente (ASSIS, 2008, p. 236). O narrador confere indeterminação aos 
pensamentos e às intenções do protagonista. Nele se instaura um ponto obscuro que o torna inacessível a si mesmo, às demais personagens e aos leitores.

Gestos de Félix em detalhe, como o charuto e o almoço, caracterizamno simultaneamente de forma social e psicológica. Compreendemos que ele não tinha ocupação a não ser pelo "repouso ativo" de classe (ASSIS, 2008, p. 237). Por sua vez, o fumo aponta para uma recusa no plano psicológico. Numa das passagens em que Félix se opõe a Meneses, ele aconselha: “- Fuma; eu já observei que o fumo impede as lágrimas, e ao mesmo tempo leva ao cérebro um nevoeiro salutar" (ASSIS, 2008, p. 253). A ironia decorre de Meneses apresentar um problema que é relevante para Félix.

Meneses tinha sido duplamente traído: pela amada e pelo amante dela, de quem era credor. Dessa forma, questiona: “- Mas quem pode adivinhar o mal, quando nos apresentam uma fisionomia risonha? Eu confiava em ambos" (ASSIS, 2008, p. 253). Félix não lida com a questão apresentada pelo amigo, e sua estratégia mostra-se falha no decorrer da trama. O problema se adensa contra o protagonista na medida em que, ao evitar a imaginação, ele não se defende do mal-estar nos relacionamentos. Pelo contrário, suas visões fazem com que ele se fie em cenários apenas possíveis, aprofundando-se no autoengano e fracassando nas interações.

À indeterminação que o narrador imprime na descrição de Félix, somase a referência aos caracteres da "desconfiança" e da "dissimulação". A dúvida subjetiva compõe seu desenho. Conforme a máxima de Shakespeare, Félix figura na "classe de homens" que "perdem o bem pelo receio de o buscar" (ASSIS, 2008, p. 314). No prólogo e no final do romance, aparece o mote de Medida por medida. Nos mesmos pontos, reflete-se sobre a vida e a morte e, consequentemente, sobre o desejo de ressurreição (que é frustrado). Considerando-se que o problema da "quase ressurreição" é central em Medida por medida, percebemos que a relação intertextual que Ressurreição estabelece com a peça não se limita à citação.

\section{Ressurreição e Medida por medida: considerações sobre a dissimulação}

A ação de Medida por medida ocorre em Viena. O duque Vicentio se disfarça com o intuito de observar o cumprimento da lei, transferindo o governo a Ângelo. O último, de caráter publicamente severo, faz recrudescer a repressão

dos costumes, ordenando a prisão e a morte de Cláudio e Julieta em função de ela ter engravidado antes de se casar. Isabela, irmã de Cláudio, intercede, 
fazendo súplicas a Ângelo. Além de não obter respostas, é extorquida. Ângelo exige a virgindade da noviça em troca da vida do irmão. Isabela confessa a chantagem a Cláudio, que não se importa com a questão moral da irmã, preferindo viver. Enquanto isso, o duque disfarçado de frei ouve o diálogo.

O duque propõe que Isabela aceite a chantagem de Ângelo, enviando Mariana em seu lugar. Descobre-se que Ângelo abandonara a moça em função da perda do dote num naufrágio. Ângelo encontra Mariana no lugar de Isabela, mas não percebe. Ainda assim, mantém a pena de morte de Cláudio. No entanto, o duque havia tramado uma solução também para o condenado, enviando a cabeça de outro prisioneiro como prova falsa. Quando revela sua identidade, o duque pretende aplicar a mesma lei - a mesma medida - que Ângelo impusera a Cláudio: a decapitação. Na solução do enredo ocorre a quase ressurreição quando se revela que Cláudio ainda vivia. Ângelo e Cláudio acabam libertos, devendo se casar com Mariana e Julieta, respectivamente. Como epílogo, o duque propõe casamento a Isabela.

Para desdobrar relações intertextuais que Ressurreição estabelece com Medida por medida, partimos de cinco pontos do enredo da peça: a matriz da identidade disfarçada; a aparência pública; a moral quanto à sexualidade; a ética nos relacionamentos; e, por fim, o tropo da ressurreição. Não obstante, devemos lembrar que a obra de Machado de Assis estabelece diálogo com a de Shakespeare por meio de rebaixamento. Cleusa Rios P. Passos observa esse tipo de apropriação em "A cartomante" (1884). No conto, a alusão a Hamlet o nobre que questiona "ser ou não ser" - destoa da figura de Camilo que “preferiu não ser nada” (PASSOS, 2009, p. 61). O efeito de estranhamento articulado pela obra machadiana quanto às referências decorre, em parte, do recuo temporal. Simultaneamente, o recuo visa ao debate de questões coetâneas, relevantes para a obra machadiana.

A matriz da identidade disfarçada em Medida por medida é ressignificada em Ressurreição por meio da dissimulação que se apresenta como fator distintivo entre as personagens na constelação do romance. O grau de maestria com que as personagens dissimulam varia de acordo com os comportamentos sexuais, o imaginário quanto ao amor romântico e a posição social no que tange ao casamento.

Dos capítulos XII ao XVIII, ocorre um imbróglio envolvendo Félix, Raquel, Meneses e Lívia devido a problemas de dissimulação. A situação se inicia quando Félix esconde o noivado por causa da "vacilação do seu espírito" (ASSIS, 2008, p. 272). Por sua vez, Lívia ora oculta, ora sugere a afeição por Félix. Meneses não tem caráter nem experiência para dissimular. Não percebe 
o noivado dos protagonistas e revela aos dois a paixão que tem por Lívia. Raquel, apaixonada por Félix, comunica a ele suspeitas de um relacionamento entre Meneses e Lívia.

No capítulo XII, "Um ponto negro", retoma-se um dos intuitos declarados na "Advertência", e o narrador desenvolve o "contraste de caracteres" que Lívia reúne em torno de si. A passagem mobiliza uma das técnicas do costume retórico de caracteres, ao contrastar dois perfis num único desenho verbal:

Tal era o contraste desses dous caracteres, que a estrela da viúva, não sei se boa ou má estrela, reuniu a seus pés. Um, se viesse a adorar um rosto hipócrita, desceria na escala das degradações, com os olhos fitos na quimera da sua felicidade; outro, ardendo pela mais angélica das criaturas humanas, quebraria com as próprias mãos a escada que 0 levaria ao céu. (ASSIS, 2008, p. 278-279)

O perfil de Félix é realçado quando ele planeja aproximar Meneses e Lívia com o intuito de testar a fidelidade da noiva. Descreve-se como o protagonista dissimula para não desencorajar o amigo (ASSIS, 2008, p. 279). De um lado, o mal-entendido de Félix faz com que ele seja o "artífice do seu próprio infortúnio” (ASSIS, 2008, p. 279); de outro, o caráter de Meneses age para a própria elevação. Lívia procura manejar a circunstância em que se encontra:

Como a confiança de Félix não se havia alterado, Lívia usava assim uma dissimulação honesta, por simples motivo de piedade e gratidão [em relação a Meneses]. Estava no seu caráter este modo de interpretar as cousas, e de as tratar assim sem grande respeito às conveniências sociais. Profanas, diria eu antes, se quisesse exprimir os verdadeiros sentimentos da viúva, que achava naquela obra de simpatia uma espécie de missão espiritual.

Às missionárias daquela espécie, se as há, desejo-lhes maior perspicácia ou mais feliz estrela. Nem a estrela nem a perspicácia da nossa heroína estavam acima do seu coração. O sentimento que a impelia era bom; o procedimento é que era errado. Ela não atentava nisso. Interrogava o rosto do médico, mais confiante e alegre que nunca, e só isto lhe bastava a seus olhos. Fossem eles menos namorados, e veriam que a tranquilidade de Félix era tão exagerada e fora dele, que não podia ser sincera. (ASSIS, 2008, p. 280, grifo nosso) 
Inferimos que Lívia dissimule não apenas em função do caráter, mas também por imposição de Félix. O "procedimento errado" não formula um juízo sobre sua atitude. Antes, aponta para uma limitação. Félix simulava tranquilidade e dissimulava a "experiência" para aproximar os caracteres correspondentes da noiva e do amigo, com o fim de "aquilatar" a "constância" e "sinceridade" da primeira (ASSIS, 2008, p. 278-279). A estrela infeliz da protagonista feminina diz respeito à posição que ela ocupa na constelação de personagens: por ser o par romântico de Félix na trama; e por ser viúva na sociedade do universo narrativo.

A “dissimulação honesta" remete ao modelo de discrição do século XVII. Segundo João Adolfo Hansen, o discreto reúne os seguintes elementos: “agudeza, prudência, dissimulação, aparência e honra” (1996, p. 83). Ele constitui um tipo intelectualmente superior, que sabe portar-se ao longo da vida para alcançar uma morte honrada (HANSEN, 1996, p. 99). A fusão da prudência com a agudeza em suas representações conota uma ideia central do Barroco. A "representação decorosa” - que tem o efeito de uma aparência verossímil - possui mais relevância na vida de relações do que a exteriorização "sincera" ou "verdadeira" dos afetos (HANSEN, 1996, p. 99).

No regime da discrição existe um senso nos termos da "dissimulação honesta", título do tratado de Torquato Accetto (1641), que a descreve como uma forma de dissimulação conveniente ao discreto católico, que retarda a demonstração da verdade em sentido platônico até o momento oportuno (ACCETTO, 2001, p. 17-18). Na apresentação à tradução brasileira Da dissimulação honesta, Alcir Pécora analisa como a prática resulta “inconcebível” para o Romantismo (apud ACCETTO, 2001, p. XIX-XX).

O narrador qualifica como "profana" a estratégia que, para Lívia, seria uma “missão espiritual” (ASSIS, 2008, p. 280). Porém, a prática é esvaziada de significado religioso num contexto burguês e escravocrata. A atitude se relaciona a um modo próprio de a protagonista "interpretar as cousas" (ASSIS, 2008, p. 280). Em suma, na caracterização de Lívia desenvolve-se a ironia na referência a dois regimes letrados. Ela destoa do sujeito romântico, pautado pela sinceridade, e da representação do discreto no século XVII, compreendida pelo decoro e pela verossimilhança.

Observamos que a figuração das personagens de Ressurreição faz referência aos caracteres, mas não se restringe a eles. Também alude a tipos sociais da família patriarcal brasileira do século XIX. Ao retomarmos a menção de Antonio Candido sobre o "tradicional ciúme ibérico" (1951, p. 309), notamos que a figuração de Félix é realçada pelo tipo que exerce direito de 
posse sobre a mulher. A partir de sua formação cultural, Félix emite juízos sobre Lívia. O amor de Meneses incide sobre a protagonista como mais um problema. O narrador afirma que o imbróglio decorre do arranjo de caracteres e das circunstâncias (ASSIS, 2008, p. 278). Contudo, a posição social de Félix no universo narrativo também tem influência no conflito.

Visualizamos um ciclo em que Félix dissimula e simula para se defender dos outros, enquanto seus pares lhe comunicam enganos em razão de circunstâncias iniciadas por ele mesmo. Sua desconfiança resulta inútil porque não o livra de ser enganado por Luís Batista no final. Pelo contrário, ao se irmanar com Luís no ponto da dissimulação, o protagonista se torna alvo dele. A diferença é que Félix não dissimula com a mesma perícia do vilão. As ações do protagonista contrariam a prática da dissimulação na sociedade de corte, em que o uso circunstancial é previsto:

Em substância, dissimular é uma profissão, da qual não se pode fazer profissão senão na escola do próprio pensamento. Se alguém usasse a máscara todos os dias, seria mais notado que qualquer outro pela curiosidade de todos; mas dos excelentes dissimuladores, que existiram e existem, não há notícia alguma. (ACCETTO, 2001, p. 20-21)

As referências à "dissimulação" em Ressurreição provêm de contextos letrados díspares em relação ao tempo da narrativa. Por meio do diálogo com Medida por medida, as estratégias de dissimulação no romance circundam o compromisso pré-matrimonial. Dado o padrão duplo de moralidade vigente no século XIX (FREYRE, 2005, p. 207-208), essas estratégias diferenciam-se conforme os gêneros. Lívia dissimula para assegurar o noivado. Félix, ao contrário, dissimula para testá-la e, em última instância, resguardar seu status. Raquel se casa após se aprimorar na dissimulação. Meneses dá um salto formativo, ao aprender a ocultar suas confissões e analisar o engodo de Luís Batista.

\section{A ironia na relação intertextual de Ressurreição com Medida por medida: o problema da ressurreição}

O uso da dissimulação pelo duque Vicentio leva à solução de conflitos morais em Medida por medida. Cláudio é salvo de uma interpretação legalista. A tirania de Ângelo é regulada. Os casamentos são arranjados. Em Ressurreição, por contraste, as práticas de dissimulação não implicam o estabelecimento de 
qualquer decoro social ou postura ética nos relacionamentos. As expectativas em torno do casamento são frustradas, e os demais temas trabalhados em diálogo com a peça de Shakespeare não recebem solução.

Félix remete a Ângelo especialmente pela ambivalência do nome e perfil. Como analisa Raquel Campos (2014, p. 217), cabe a Félix confirmar seu antropônimo de acepção feliz e fértil ao ser contrastado pelo amor de Lívia. Embora ele aconselhe suprimir o coração por cirurgia (ASSIS, 2008, p. 253), rende-se ao caráter amoroso da noiva: "Quando Félix chegou a encarar-lhe o coração, sentiu a fascinação do abismo, e caiu nele" (ASSIS, 2008, p. 262). Por sua vez, o nome de Ângelo comporta os significados de anjo e diabo (SCHANZER, 1963, p. 95): "Podemos escrever 'Anjo Bondoso'/ Nos cornos do diabo/ Sem fazê-lo seu lema real” (SHAKESPEARE, 2015, p. 51). Sua outra face aparece no solilóquio em que se questiona sobre o amor por Isabela: "Que fazes, Ângelo? Antes, quem és?/ Teu desejo por ela vem das coisas/ Que a fazem boa? Deixe que seu irmão viva!” (SHAKESPEARE, 2015, p. 51).

Na composição de Félix e Ângelo existe um contraste entre a aparência pública e o coração. No protagonista shakespeariano há uma autoimposição para aparentar falta de humanidade (SCHANZER, 1963, p. 92). Já o narrador machadiano ressalta na apresentação do "herói”: "Duas faces tinha o seu espírito, e conquanto formassem um só rosto, eram todavia diversas entre si, uma natural e espontânea, outra calculada e sistemática” (ASSIS, 2008, p. 237). Uma diferença reside em Félix ser "vadio" e "desambicioso" (ASSIS, 2008, p. 237), enquanto Ângelo estima o exercício público da lei (SHAKESPEARE, 2015, p. 54). Não é difícil ponderar que a divergência decorra de um rebaixamento na composição de Félix, relacionado a um tipo social brasileiro do século XIX. Félix é um senhor e herdeiro. Para de trabalhar após um lance de sorte (ASSIS, 2008, p. 237).

A principal diferença, contudo, decorre da frustração articulada pela trama de Ressurreição em diálogo com a de Medida por medida. Ambos os protagonistas se valem da aparência pública para exercer domínio sobre os outros. O problema retorna aos dois: Ângelo é desmascarado e julgado pelo duque; enquanto Félix teme ser julgado pela opinião pública. Em Shakespeare há absolvição e reparo dos contratos de casamento. De acordo com a cosmovisão implicada em Medida por medida, o duque é um representante de Deus no governo, promovendo a quase ressurreição de Cláudio. Sean Benson (2009, p. 70) defende que esta é a peça de Shakespeare que mais abertamente trata da questão de vida ou morte. 
Por contraste, em Ressurreição, o rompimento do noivado invalida a possibilidade de reparo e redenção. No início da trama, Félix argumenta "estar abaixo do papel de redentor" (ASSIS, 2008, p. 241). Suas palavras se voltam contra ele: "[...] o seu coração, se ressurgiu por alguns dias, esqueceu na sepultura o sentimento da confiança e a memória das ilusões" (ASSIS, 2008, p. 314). Como não pode redimir a si mesmo, ele não apresenta a possibilidade do casamento com Lívia. Figura-se a dissimetria de Félix no tratamento de si e dos demais. Além de imputar o papel de redentora à Lívia, ele se encontra insatisfeito com o "milagre" operado por ela (ASSIS, 2008, p. 274-275).

Se voltarmos o foco para Lívia, por sua vez, inferimos sua perspectiva quanto à ressurreição. Ao confessar as desilusões no casamento anterior, ela espera retornar à vida. Uma pergunta que geralmente se impõe à personagem viúva na obra machadiana é se casará novamente. Caso não, vive entre os mortos. Caso sim, complica-se com a aparência de infidelidade. Entre os caracteres de Thomas Overbury, por exemplo, encontramos os da "viúva virtuosa" e "ordinária" (apud A BOOK OF "CHARACTERS", 1924, p. 149-150). No último, lê-se: "O fim do seu marido começa em lágrimas, e o fim de suas lágrimas começa com um marido" (apud A BOOK OF "CHARACTERS", 1924, p. 150). Porém, a composição de Lívia não se esgota na tipologia. Félix é quem por vezes a vê com os "caracteres de uma loureira vulgar" (ASSIS, 2008, p. 267). Na carta de Luís Batista, sobretudo, acentua-se o suposto caráter negativo de Lívia: "És amado como era o outro; serás humilhado como ele. No fim de alguns meses terás um Cireneu para te ajudar a carregar a cruz, como teve o outro, por cuja razão se foi desta para a melhor. Se ainda é tempo, recua!” (ASSIS, 2008, p. 308).

Observe-se a alusão à ressurreição: "Simão Cireneu é a personagem que ajuda Jesus Cristo na Via Crucis, carregando-lhe a cruz por um trecho do percurso". ${ }^{1}$ No discurso de Luís Batista, Lívia seria a cruz, e seu marido, Cristo. Trata-se da acepção do mártir traído. O problema da ressurreição é central para a conversa entre Félix e Lívia no capítulo XI. Notamos que apesar de o título deste capítulo ser "O passado", os protagonistas repetem erros no presente. Ademais, Viana coloca questões sobre o futuro do casal: “- Receio disse ele - que a Lívia se case mais tarde ou mais cedo" (ASSIS, 2008, p. 275).

A descrição de Viana como um "parasita por direito divino" leva-nos a desconfiar de suas motivações (ASSIS, 2008, p. 239). As "combinações de

\footnotetext{
1 Trecho retirado do site Citações e alusões na ficção de Machado de Assis. Disponível em: $<$ http://machadodeassis.net>. Acesso em: 30 set. 2020.
} 
horticultura" que ele faz no capítulo XI (ASSIS, 2008, p. 275) convergem para outra urdidura: a da "aliança de família" (ASSIS, 2008, p. 255). Em Memória das ilusões Amanda Rios Herane (2011) conclui que, embora os protagonistas idealizem um casamento resguardado das obrigações sociais, Viana lhes apresenta um obstáculo. O parasita compreende o casamento da irmã como "ato social" que acarreta status (HERANE, 2011, p. 81).

Se tivermos em mente a referência intertextual a Medida por medida, cria-se um paralelo em que Félix remete a Ângelo, Lívia a Isabela e Mariana, e Viana a Cláudio. Lívia guarda semelhança com Isabela ao ser descrita por menção à religiosidade e ao martírio. Por fim, é abandonada como Mariana. Viana tenta aproveitar-se da irmã, lembrando Cláudio. Félix rompe o noivado com um "último golpe", assumindo o papel de tirano. Ele resguarda sua posição social, ao não formar uma família nuclear nem estabelecer laços com agregados. A ligação entre Lívia e Viana, aliás, encobre aquela mais profunda entre ela e Luís, o menino. Este lembra seu casamento anterior e potencialmente exclui Félix. A fantasia de ameaça que o filho da noiva representa, para o protagonista, é condensada pela homonímia com o vilão do romance, Luís Batista.

Pelo realce que Machado criou entre a constelação de personagens e a trama de seu primeiro romance e a peça de Shakespeare, aclaramos níveis intertextuais na ironia do título de Ressurreição. A mobilização que o romance desenvolve de referências antigas - como o faz significativamente com o texto shakespeariano - não apenas valida o estudo de caracteres, como também o recria em chave irônica. A falha das expectativas de ressurreição demonstra ser calculada pelo romance de 1872, segundo especificidades de papéis sociais e de gênero na família patriarcal do período.

Ao dialogar com a solução do enredo por meio do casamento em dois registros diferentes - na prosa romântica coetânea e em Shakespeare Ressurreição mina esse procedimento. O diálogo em chave negativa potencialmente nos leva a questionar o paradigma romântico oitocentista, bem como a refletir sobre o final de Medida por medida. O "pensamento de Shakespeare" destacado pelo texto machadiano provém de Lúcio (ASSIS, 2008, p. 236). Por um lado, sua fala é encorajadora, levando Isabela a recorrer da sentença de Cláudio. Por outro lado, Lúcio é quem compara o casamento com uma mulher sexualizada à morte no final da peça: "Casar com puta, meu senhor, é morte/ Pior que açoite e forca” (SHAKESPEARE, 2015, p. 134). Observe-se que as falas da personagem pertencem ao registro cômico. Em Ressurreição, por sua vez, o mote é ressignificado de acordo com uma 
tonalidade melancólica. A máxima condensa o gesto do herói que contribui para a própria ruína em função da dúvida subjetiva. A composição negativa do protagonista, como o sol que representa um passo para a morte, alastra-se para uma constelação de personagens arranjada em torno de uma frustração.

\section{Referências}

A BOOK OF "CHARACTERS" from Theophrastus. Compiled and Translated by Richard Aldington. London: George Routledge \& Sons LTD.; New York: E.P. Dutton \& Co., 1924.

ACCETTO, Torquato. Da dissimulação honesta. Trad. Alcir Pécora. São Paulo: Martins Fontes, 2001.

ASSIS, Machado de. Obra completa em quatro volumes. 2. ed. Rio de Janeiro: Nova Aguilar, 2008.

- Machado de Assis: crítica literária e textos diversos. Organização de Sílvia Maria Azevedo, Adriana Dusilek e Daniela Mantarro Callipo. São Paulo: Editora Unesp, 2013.

BENSON, Sean. Shakespearean resurrection: the art of almost raising the dead. Pittsburgh: Duquesne University Press, 2009.

CAMPOS, Raquel. Homonímia e ironia do nome em Ressurreição. Machado de Assis em Linha: revista eletrônica de estudos machadianos, São Paulo, v. 7, n. 14, p. 209-228, jun. 2014. Disponível em: <https://www.scielo.br/scielo.php?script=sci_arttext\&pid=S198368212014000200014>. Acesso em: 30 set. 2020. doi:10.1590/S198368212014000200014.

CANDIDO, Antonio. The Brazilian Family. In: SMITH, T. Lynn; JENKINS, Rob. Brazil: portrait of half a continent. New York: Dryden Press, 1951. p. 291-312.

CITAÇÕES E ALUSÕES NA FICÇÃO DE MACHADO DE ASSIS. Site. Disponível em: <http://machadodeassis.net $>$. Acesso em: 30 set. 2020.

EDER, Jens; JANNIDIS, Fotis; SCHNEIDER, Ralf. (Eds.). Characters in fictional worlds: understanding imaginary beings in literature, film, and other media. Berlin; New York: Walter de Gruyter, 2010.

FREYRE, Gilberto. Sobrados e mucambos: decadência do patriarcado rural e desenvolvimento do urbano. 15. ed. São Paulo: Global Editora, 2005.

GUIMARÃES, Hélio de Seixas. Os leitores de Machado de Assis: o romance machadiano e o público de literatura do século 19. São Paulo: Nankin Editorial; Editora da Universidade de São Paulo, 2004.

HANSEN, João Adolfo. O discreto. In: BORNHEIM, Gerd et al. Libertinos libertários. São Paulo: Companhia das Letras, 1996.

HERANE, Amanda Rios. Memória das ilusões: um estudo de Ressurreição, primeiro romance de Machado de Assis. 2011. 119 f. Dissertação (Mestrado em Literatura 
Brasileira) - Faculdade de Filosofia, Letras e Ciências Humanas, Universidade de São Paulo, São Paulo, 2011.

LA BRUYĖRE, Jean de. Caracteres. Rio de Janeiro: Ed. Athena, 1937.

PASSOS, Cleusa Rios Pinheiro. As armadilhas do saber: relações entre literatura e psicanálise. São Paulo: Editora da Universidade de São Paulo, 2009.

SCHANZER, Ernest. The problem plays of Shakespeare: a study of Julius Caesar, Measure for measure, Antony and Cleopatra. New York: Schocken Books, 1963.

SHAKESPEARE, William. Medida por medida. Trad. Barbara Heliodora. Rio de Janeiro: Nova Fronteira, 2015.

William Shakespeare: the complete works. London: CRW, 2005.

TRÖHLER, Margrit. Multiple protagonist films: a transcultural everyday practice. In: EDER, Jens; JANNIDIS, Fotis; SCHNEIDER, Ralf. (Eds.). Characters in fictional worlds: understanding imaginary beings in literature, film, and other media. Berlin; New York: Walter de Gruyter, 2010. p. 459-477.

ANA CAROLINA SÁ TELES é mestre e doutora em Literatura Brasileira pela Universidade de São Paulo. 0 artigo resulta da tese "Personagens machadianas e suas constelações em Ressurreição, Helena e Dom Casmurro", defendida em 2018 e financiada pela FAPESP (Processo 2014/18486-0) e pelo CNPq (Processo: 140184/2015-5).

(iDhttps://orcid.org/0000-0001-5110-2590 E-mail: ana.teles@alumni.usp.br

Recebido: 09.06.2020

Aprovado: 13.10 .2020 